\title{
Unsaturated seepage analysis at the Guayabo National Archaeological Monument, Costa Rica
}

\author{
Rafael Baltodano-Goulding ${ }^{1,2} *$ \\ ${ }^{1}$ LabUnsat, Civil Engineering Department, University of Costa Rica \\ ${ }^{2}$ Construction Engineering Department, Costa Rica Institute of Technology, Costa Rica
}

\begin{abstract}
The Guayabo National Archaeological Monument is considered one of the most important historical and political ceremonial centers of pre-Columbian Costa Rica, Central America, and it depicts the ingenuity and the quality of life of Costa Rica's inhabitants between $800 \mathrm{BC}$ and AD 1400. This site was named International Historic Civil Engineering Landmark in 2009 by the American Society of Civil Engineers (ASCE). Evaluation of the unsaturated flow at the Northwestern slope using a two-dimensional model was performed. It was determined from field and modeling that at a relatively shallow depth the soil is relatively impermeable; thus, producing a large amount of run-off that tends to deteriorate the archaeological structures, and induce landslides. As part of the site investigation, exploratory borings were performed, and piezometers were installed in the upper, middle, and bottom parts of the slope. A series of laboratory testing was also performed to obtain index soil and permeability properties. The soil-water characteristic used to develop the K-Curve was also obtained. Additionally, a groundwater model was created using the geotechnical model and a water balance analysis for the area, where different scenarios of recharge and precipitation were analyzed taking into consideration the observed data. The volume of slope run-off through towards the archaeological site was estimated and the areas where it emerges, as well as the field groundwater.
\end{abstract}

\section{Introduction}

The Guayabo National Archaeological Monument is considered one of the most important historical and political ceremonial centers of pre-Columbian Costa Rica, Central America, and it depicts the ingenuity and the quality of life of Costa Rica's inhabitants between $800 \mathrm{BC}$ and AD 1400. This site was named International Historic Civil Engineering Landmark in 2009 by the American Society of Civil Engineers (ASCE), because advanced civil engineering infrastructure, for the time, has been revealed by the restoration activities in the monument.

The restored hydraulics infrastructure of the preColumbian era can still store, conduct, and evacuate water from the hillside. However, the flow patterns along the Northwestern slope, shown in Figure 1, are still not well-understood, making it difficult to plan water control structures to protect the monument. Additionally, there is a risk that high-intensity rains will cause landslides that will put at risk the archaeological findings at the site.

Several experts in archaeological monuments agree that, if the pre-Columbian hydraulic system is restored, the runoff water and groundwater will be better controlled, and this will likely increase the slope's stability. $[1,2,3]$. Therefore, it is necessary to model the groundwater component, which represents a considerable contribution to the flow that affects hydraulics structures.

These analyses are imperative to design future restoration activities aiming to re-establish adequate hydraulics storage and piping system so the country's cultural heritage can be preserved.

The main focus of this research is to evaluate the behavior of groundwater through the northwest slope of the Guayabo National Monument using a twodimensional flow model. In order to construct this model, an estimation of the geological-geotechnical and hydraulic properties of the soil was performed by means of laboratory and field tests. Later on, areas most affected by water were identified.

\section{Site Characterization}

The soil types found in the study area are classified as sandy clays with high plasticity. The soils increase the fine percentage as a function of depth. In addition, falling head laboratory permeability tests were performed.

The case of study is located on a basal geological substrate, composed by a lahar [4] consisting of a mudflow, which can be classified as a sand slime with high plasticity and corresponds to a non-consolidated matrix with fragments of basaltic andesitic lavas. The site lithology is characteristic of soils with very low 
permeability and slow infiltration. Figure 2 shows evidence of pluvial erosion patterns due to this low infiltration characteristics. These erosion patterns can be observed in the southern edge of the Caragra road and in the riverbed of Brook Chanchera [4] (lower parts of the hillside).

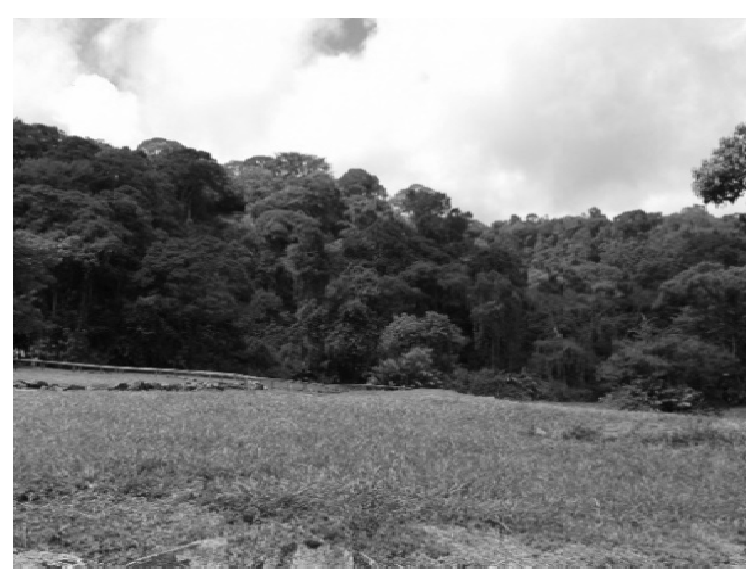

Fig. 1. Northwest hillside of Guayabo Archaeological National Monument.

A series of falling head permeability test was performed in the laboratory using a rigid wall permeameter. Additionally, a series of Porchet permeability test was performed inside the borings where the piezometers were installed in the field. Locations of the borings are shown in Table 1. Permeability values around $2.01 \mathrm{E}-2 \mathrm{~cm} / \mathrm{s}$, which is equivalent to $17.41 \mathrm{~m} /$ day, were obtained for shallow soils, which is a typical value for loamy soils [5]. As it can be inferred from the permeability of shallow soils, the flow rate throughout these materials is typical of sandy soils. Therefore, water should be able to infiltrate and flow with relative ease through these materials. On the other hand, the stratum from the surface up to $1 \mathrm{~m}$ deep exhibited smaller permeability values around 1.79 E-4 cm/s, equivalent to $0.154 \mathrm{~m} /$ day. This saturated permeability value remains within the proper range of loamy soils, but infiltration through this material is expected to be slower.

The hillside at middle-height exhibited a very permeable layer, which agrees with the observations on the site and the evident runoff water at the middle part of the slope, near the exploration borings. It is important to mention that three piezometers were installed on the slope: at the top, mid-height, and bottom, as shown in Table 1, and that the water levels in the piezometer in the middle of the slope showed no variation during the year.

In addition to the study of the mechanical properties of the soil, a water balance was performed to determine the recharge of the area. It is important to consider that before rain infiltration occurs, there is water in the pores of the soil in the form of moisture. Therefore, the amount of water in the soil corresponds to the sum of the initial moisture values obtained, closely related to the capacity of the soil to retain water and the infiltrated water. The water that is affected by evapotranspiration from the slope and the final moisture of the soil will be the water that does not recharge towards the water table. Figure 3 shows variations of these values through the year, along with the recharge water of the groundwater flow of the slope obtained using the Schosinsky methodology [6]. It can be observed from Figure 3 that humidity has a constant behavior with an offset in the month of February, which corresponds to the dry season, and the rainfall deficit produces a reduction in the soil moisture.

Table 1. Coordinates for the three exploration points in the CRTM05 system.

\begin{tabular}{|c|c|c|}
\hline \multirow{2}{*}{ Exploration point } & \multicolumn{2}{|c|}{ Flow rate (liters per second) } \\
\cline { 2 - 3 } & $\mathrm{X}$ & $\mathrm{Y}$ \\
\hline 1 (Top of the slope) & 533846.300 & 1102804.898 \\
\hline $\begin{array}{c}\text { 2 (Mid-height of the } \\
\text { slope) }\end{array}$ & 533791.481 & 1102803.741 \\
\hline 3 (Toe of the slope) & 533757.446 & 1102854.584 \\
\hline
\end{tabular}

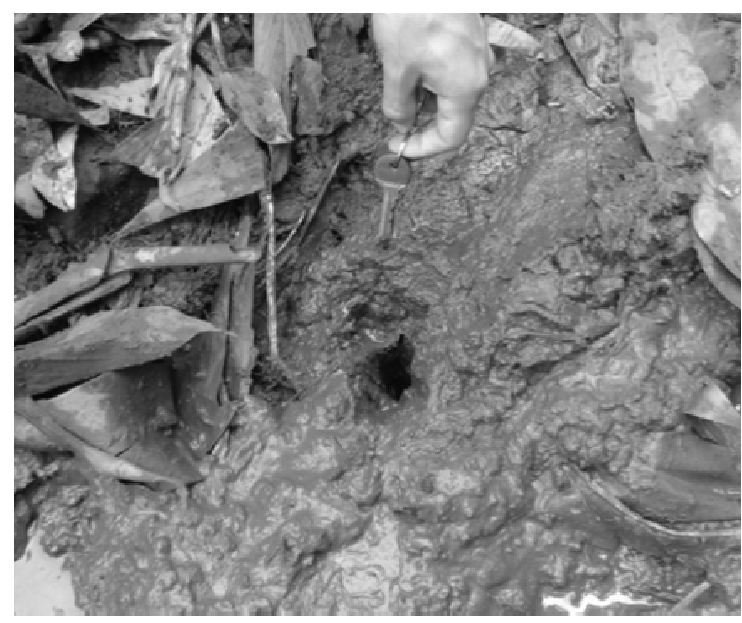

Fig. 2. Superficial water in the middle part of the slope due to the low permeability of the surface layer.

Recharge values in Figure 3 show the expected behavior. The recharge has a maximum value at the end of the year, considering the type of precipitation in this part of the world, rain tends to infiltrate rather than to run-off. This tendency also agrees with the measurements in the piezometers, which reached their maximum level in November. Using a representative point of the slope understudy, a recharge value was determined at $2.18 \mathrm{E}-08 \mathrm{~m} / \mathrm{s}$, corresponding to the month with the highest static levels, recorded in the three piezometers placed in the field.

Table 2 and Table 3 show the soil hydraulic properties used to develop the K-curve, acquired using a lab tensiometer. Soil specimens to develop both curves were attained from a depth of one meter, and at the surface, and exhibited similar hydraulic conductivity 
values for the suction range greater than $10 \mathrm{kPa}$. Soil sample 1 was taken from the toe of the slope and soil sample 2 is taken from the toe of the slope. The soil hydraulic conductivity was estimated using the van Genuchten \& Mualem equation [7].

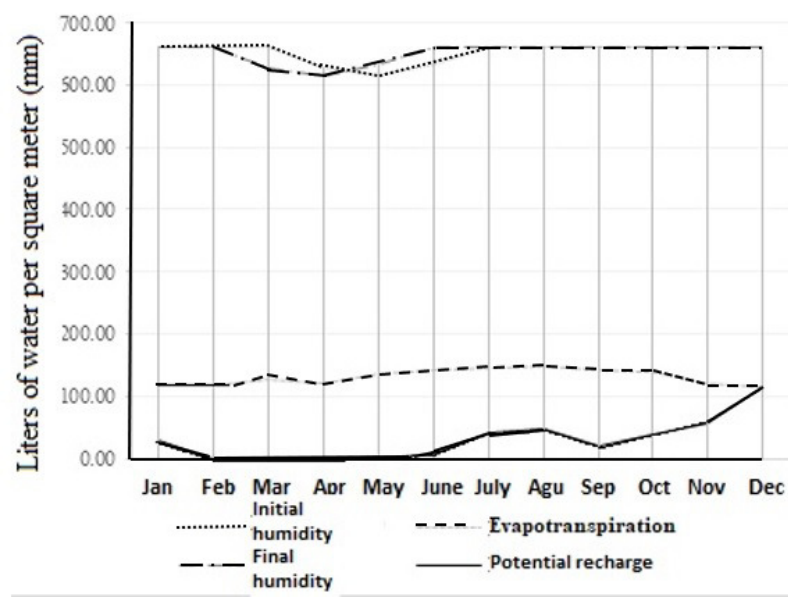

Fig. 3. Monthly variation of initial moisture, final moisture, actual evapotranspiration, and potential recharge.

Table 2. Data used to develop the K-Curve for soil sample 1, using the van Genuchten \& Mualem Model (1981).[7]

\begin{tabular}{|c|c|c|c|c|c|}
\hline \multirow{2}{*}{ Parameter } & \multicolumn{5}{|c|}{ Number of samples } \\
\cline { 2 - 6 } & 1 & 2 & 3 & 4 & 5 \\
\hline Suction (kPa) & 2.2 & 5.0 & 13.5 & 28.0 & 20.1 \\
\hline $\begin{array}{c}\text { Potential } \\
\text { matrix (m) }\end{array}$ & 0.22 & 0.42 & 1.38 & 2.86 & 2.05 \\
\hline $\begin{array}{c}\text { Effective } \\
\text { saturation }\end{array}$ & 0.594 & 0.422 & 0.268 & 0.190 & 0.223 \\
\hline $\begin{array}{c}\text { Hydraulic } \\
\text { Conductivity } \\
(\mathrm{m} / \mathrm{s})\end{array}$ & $\begin{array}{c}7.30 \\
\text { E-7 }\end{array}$ & $\begin{array}{c}6.69 \\
\text { E-8 }\end{array}$ & $\begin{array}{c}3.06 \\
\text { E-9 }\end{array}$ & $\begin{array}{c}3.05 \\
\text { E-10 }\end{array}$ & $\begin{array}{c}8.79 \\
\text { E-10 }\end{array}$ \\
\hline
\end{tabular}

Table 3. Data used to develop the K-Curve for soil sample 2, using the van Genuchten \& Mualem Model (1981).[7]

\begin{tabular}{|c|c|c|c|c|c|}
\hline \multirow{2}{*}{ Parameter } & \multicolumn{5}{|c|}{ Number of samples } \\
\cline { 2 - 6 } & 1 & 2 & 3 & 4 & 5 \\
\hline Suction (kPa) & 12.5 & 15.5 & 31.5 & 41.0 & 52.0 \\
\hline $\begin{array}{c}\text { Potential } \\
\text { matrix (m) }\end{array}$ & 1.28 & 1.58 & 3.21 & 4.18 & 5.31 \\
\hline $\begin{array}{c}\text { Effective } \\
\text { saturation }\end{array}$ & 0.278 & 0.252 & 0.180 & 0.159 & 0.142 \\
\hline $\begin{array}{c}\text { Hydraulic } \\
\text { Conductivity } \\
(\mathrm{m} / \mathrm{s})\end{array}$ & 3.46 & 1.76 & 1.86 & $\begin{array}{c}8.06 \\
\mathrm{E}-11\end{array}$ & $\begin{array}{c}3.78 \\
\mathrm{E}-11\end{array}$ \\
\hline
\end{tabular}

Laboratory testing was performed to develop the soilwater characteristic curve shown in Figures 5 and 6 . As it was mentioned before, there are two types of silty sand present on the site, with an upper, more permeable layer and a lower, less permeable. These curves were used to develop the $\mathrm{K}$-curve used in the numerical model to study the underground seepage on the slope. Because of the difference in fine content, two materials that exhibit the same soil classification and with relatively similar grain size distribution may present very different hydraulic behavior. Table 4 shows the fitting parameter used for the van Genuchten \& Mualem equation, which was used to develop the K-Curve and the Soil-water retention curve. Since most of the measured points are in the wetter part of the soil-water retention curve the fitting parameters were selected using the database and recommended values for this type of soil in the RECT computer program of the Environmental Protection Agency of the United States of America [8].

Table 4. Measured hydraulic conductivity and van Genuchten \& Mualem Model (1981) model parameters for both soil samples.

\begin{tabular}{|c|c|c|c|c|}
\hline \multirow[b]{2}{*}{$\begin{array}{c}\text { Soil } \\
\text { sample }\end{array}$} & \multirow{2}{*}{$\begin{array}{c}\text { Saturated } \\
\text { hydraulic } \\
\text { conductivity } \\
(\mathrm{m} / \mathrm{s})\end{array}$} & \multicolumn{3}{|c|}{ Fitting parameters } \\
\hline & & $\alpha$ & $\mathrm{n}$ & $\mathrm{m}$ \\
\hline 1 & $2.01 \mathrm{E}-4$ & $11.51 / \mathrm{m}$ & 1.474 & 0.321 \\
\hline 2 & $1.79 \mathrm{E}-6$ & $11.51 / \mathrm{m}$ & 1.474 & 0.321 \\
\hline
\end{tabular}

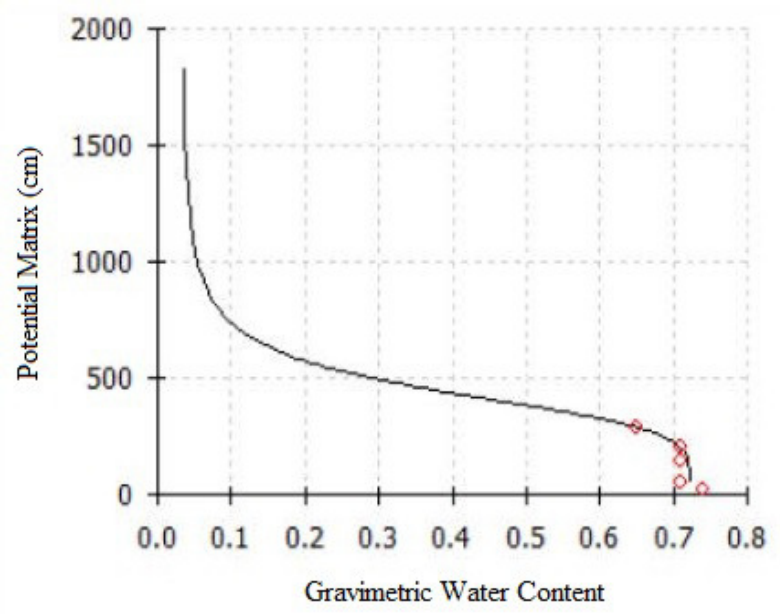

Fig. 4. Upper sandy silt Soil-Water Characteristic Curve. 


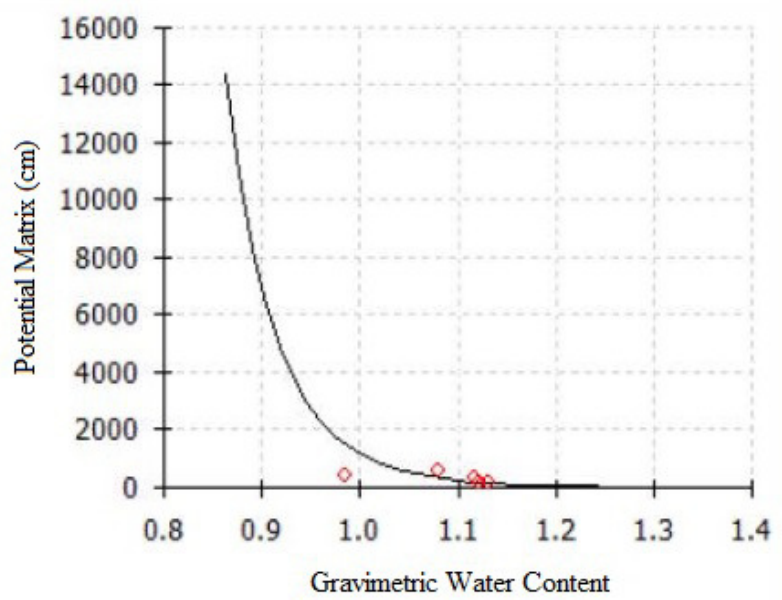

Fig. 5. Lower sandy silt Soil-Water Characteristic Curve.

\section{Seepage Analysis}

An underground seepage analysis requires an understanding of the flow directions and magnitude. Figure 6 shows the overview of groundwater flow patterns considering equipotential curves every $2 \mathrm{~m}$. In this figure, it is important to notice that the hydraulic gradient of the water mantle in the area is approximately $0.52 \mathrm{~m} / \mathrm{m}$, quite high considering the tendency of groundwater behavior. Therefore, it is expected that the flow rates would be quite high in this zone. It can be noticed how the gradient of the equipotential curves decreases as the height of the slope decreases, i.e., upslope the gradient is high, so the speeds are lower in this zone. In the lower part, due to the sudden change of topography, the curves start to space out, i.e., there is a hydraulic lower gradient.

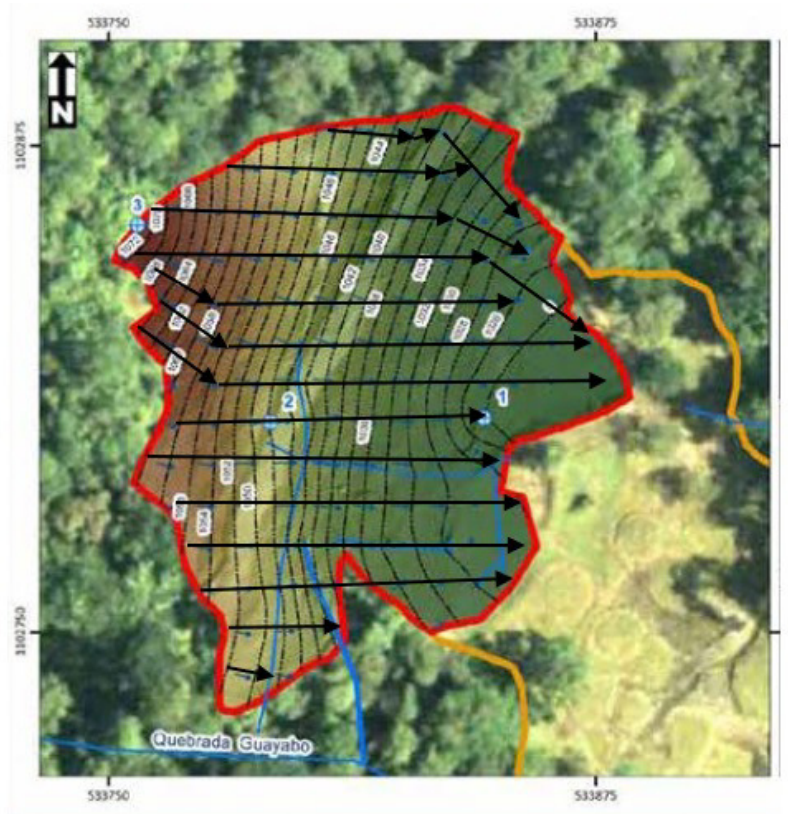

Fig. 6. Flow pattern along the slope.[7]
Three different cross-sections (profiles 1, 2, and 3) along the slope were analyzed using the finite element groundwater seepage analysis capabilities of the Slide ${ }^{\circledR}$ software from Rocscience. Two different scenarios: unsaturated field conditions for November, and unsaturated field conditions for November plus the calculated infiltration. The first scenario showed suction values of $19.61 \mathrm{kPa}$, and the second scenario showed values up to $24.5 \mathrm{kPa}$. It was observed from the models that the suction values are representative of near saturation at the mid-height of the slope and then increase again in the lower part. Table 5 shows the flow rates calculated for the three profiles at the top, middle, and bottom of the slope. Figure 7 shows the profiles selected for modeling. It is worth mentioning that the software capabilities allow for the consideration of the infiltration rates estimated from the water balance analysis obtained from the Schosinsky Method [6], but does not allow to consider the runoff water. This must be estimated otherwise.

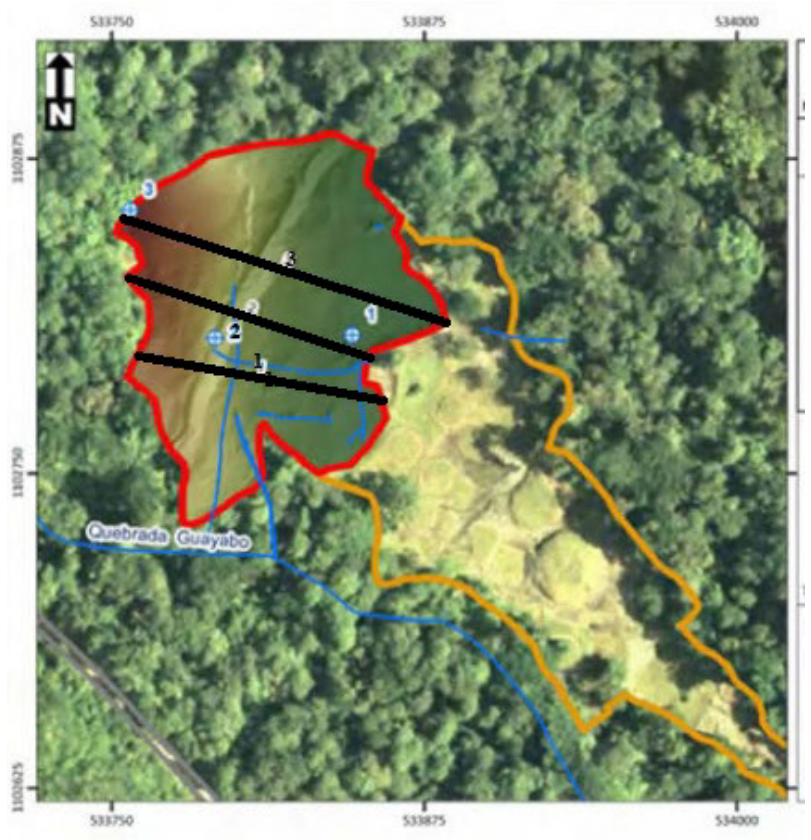

Fig. 7. Profiles selected to perform the modeling.[7]

The models revealed that despite the presence of high precipitation, there is an unsaturated zone near the surface at the top and toe of the slope, so it is expected that the water that emerges in the middle part of the slope will turn into runoff water that recharges the surface water bodies identified on the field.

Profile 1 shows a sharp decrease in the middle part of the slope, which is consistent with field observations. It means that this zone does not have groundwater recharge, but most of the water becomes part of the runoff water. Groundwater flow increases again in the lower zone, so there is a section between the middle and lower zone of the slope where the water can infiltrate again. Profile 3 showed similar behavior, but the midheight estimated flow drop is not as big. Therefore, it can be concluded that the superficial groundwater flow rate 
increases in the lower zone of the hillside, as it can be appreciated in Table 5.

Table 5. Flow rate for different soil profiles and different locations.

\begin{tabular}{|c|c|c|c|}
\hline \multirow{2}{*}{ Soil Profile } & \multicolumn{3}{|c|}{ Flow rate (liters per second) } \\
\cline { 2 - 4 } & $\begin{array}{c}\text { Top of the } \\
\text { slope }\end{array}$ & $\begin{array}{c}\text { Mid-height } \\
\text { of the slope }\end{array}$ & $\begin{array}{c}\text { Toe of the } \\
\text { slope }\end{array}$ \\
\hline 1 & 28.46 & 0.47 & 94.94 \\
\hline 2 & 17.71 & 34.08 & 81.69 \\
\hline 3 & 26.31 & 10.50 & 16.67 \\
\hline
\end{tabular}

The volume of water observed on site is greater than the one calculated by the models probably because the run-off needs to be added to the superficial groundwater flow rate.

Speed profiles in Figure 8 show how water flow only appears in the surface of the permeable layer of the slope. In addition, this occurs only between the upper and the middle zone of the slope, so it can be interpreted that ground recharges in the upper zone of the slope and these speeds discharge in the middle zone as runoff water. The speed ranges match the observed behavior in the equipotential lines of the three profiles. In profile 1 speeds of $3.88 \mathrm{~cm} /$ day have been reached, while profile 2 shows speeds of $4.84 \mathrm{~cm} /$ day and profile 3 of 4.32 $\mathrm{cm} /$ day.

The permeable surface materials prevent infiltration towards the rocky base. Therefore, at the zones where the permeable thickness becomes smaller, water does not completely infiltrate causing the water flow rates to be high and the restored zones to be flooded. This occurs while the lower soil stratum has not reached saturation, because of the waterproof seal identified in the samplings.

In the upper zone of the slope, soil permeability gradually increases as the depth increases to reach the less permeable layer. However, this change occurs more quickly in profile 2 , due to surface water flow in this profile is larger as it was observed at the site.

The middle zone of the slope showed lower values of permeability this explains why in this area starts the runoff water of the slope, at this point infiltration is very difficult.

The lower zone of the slope exhibits values of saturated permeability in the restored zone, except in profile 2, where it is observed that there are soil zones characterized by degrees of saturation values under $100 \%$.

It should be taken into consideration that the permeability profiles were obtained under conditions with precipitation so that near-surface points would be expected to also exhibit high permeability values because of increased soil moisture. However, the results allow confirming that when water infiltrates it contacts abruptly with a layer less permeable in a shallow depth, so the zones of a greater degree of saturation appear below this layer and not up.
Although water is expected to flow through the soil as soon as it saturates the low points of the permeable layer, water balance analysis indicates that soil water retention is very large, so water cannot move freely. In addition, it is necessary to consider the proximity of the less permeable stratum with the surface, so water that runoff is the one that could not infiltrate and the one that accumulates near the lower permeability silty layer. This explains why groundwater flow rates are so small and runoff water is high under precipitation conditions.

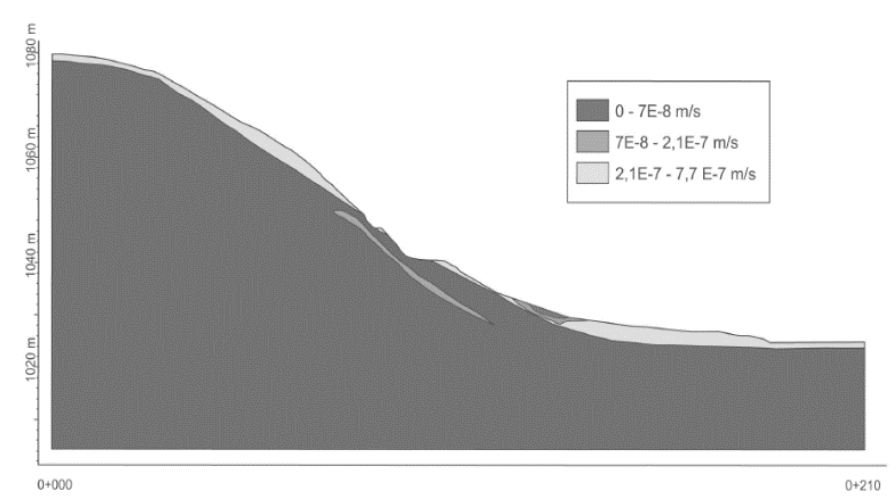

Fig. 8. Speed profiles for the slope sections analyzed.

The seepage analysis also showed that the speed vectors are larger in magnitude between the upper and medium zone of the slope, and close to the medium zone. This means that after the permeable layer is recharged in the upper zone there is a water outcrop in the middle zone of the slope, and consequently, there is an increase in runoff water. In the lower zone, vectors appear again in profiles 1 and 3 , but in a smaller magnitude than upper slope zones.

\section{Conclusions}

Geotechnical site exploration on the northwest slope of the Guayabo National Archaeological Monument provided a better understanding of groundwater water behavior in the area.

Because the water balance methodology used [6] is discrete and non-spatial; the potential recharge value was determined at three different points, already defined in Table 1. An important characteristic of this method is that it calculates the potential recharge of the soil to aquifers. The point chosen was the one in the middle zone of the slope because represents critical conditions according to field observations.

November was identified as the month with the highest groundwater recharge since the measurements in the piezometers reached maximum levels. Therefore, the conditions observed during this month were modeled to determine the maximum ground water flow for the whole year.

The results of the water balance and the measurements in the piezometers indicated that the water levels are not high, so the soil is most likely not saturated at shallow depths regardless of the high intensity of the precipitation common to the area. This is consistent with 
the natural moisture contents measured from soil samples obtained during the geotechnical exploration.

The upper stratum has a saturated permeability value of $2 \mathrm{E}-1 \mathrm{~cm} / \mathrm{s}$, while the underlying stratum has a value of $1.79 \mathrm{E}-4 \mathrm{~cm} / \mathrm{s}$. Therefore, the lower stratum prevents water infiltration because both layers have hydraulic conductivities with a different order of magnitude, suggesting that infiltration happens only in the upper stratum.

Both soil-water characteristic curves obtained displayed a typical behavior of fine soils. The initial section of the curve is very sensitive to the moisture changes produced by the presence of air into the pores. Therefore, the curves obtained described the hydraulic behavior of sampled soil strata when moisture changes occur on site. A wider range of suctions at drier water contents must be obtained in future research, in order to develop soil-water characteristic curves and K-curves that are more representative of the soil present in the site.

The equipotential curves modeled show a greater gradient in the upper zone of the slope than in the lower zone producing higher speeds that tend to favor pluvial erosion and reduce infiltration.

Flow rates of 84.97 liters/day were obtained in profile 1 at the toe of the slope; 3.0 liters/day for profile 2 , and 0.91 liters/day for profile 1 , under conditions without precipitation. This contrasted with values obtained in the upper slope zone of 3.31 liters/day in case of profile 1, 11.13 liters/day for profile 2 and 12.46 liters/day for profile 3 . Flow rates at the bottom of the slope in profile 1 did not show significant variations as a function of precipitation. Consequently, the rain infiltrates very little in this section, draining superficially from the upper zone of the slope.

Discharge areas in the restored archaeological zone of the monument have a small contribution to groundwater; however, the greater volume of water that reaches this area is through runoff water.

The groundwater flow occurs in the most superficial layers, while the infiltration to the low permeability silt layer is reduced.

The shallow depth of the layer where the water can infiltrate causes that under heavy rain the soil infiltration capacity gets reduced, consequently runoff is the dominant mechanism through the surface of the hillside and has high drag capacity.

The degree of saturation in the hillside increases from the lower stratum towards the surface due to the low permeability materials at the bottom of the profile acting as a seal. These changes in the degree of saturation have a significant effect on the seepage pattern in the hillside as the soil nearest to the surface has higher suction values.

The high volume of water that floods the toe of the slope and the archaeological structures at the bottom, is due mainly to runoff water and not groundwater, because high suctions in the surficial soils and high-intensity precipitation in the area impede proper rain infiltration.

\section{References}

1. C. Castaño, Procedimientos para la restauración del Monumento Nacional Guayabo de Turrialba, Costa Rica. Documento inédito (FAO, INDERENA. Bogotá, Colombia, 1988).

2. A. Narváez, R. Morales, (2008). Monumento Nacional Guayabo. Consultoría sobre conservación arqueológica. Documento inédito, (ProParques. San José, Costa Rica, 2008).

3. Y. Jáidar, T. Velasco, T. Visita al Monumento Nacional Guayabo de Turrialba, Costa Rica. Informe. Documento inédito, (CNCPC-INAH. México DF, Mexico, 2011).

4. L. Obando, and G. Peraldo, Rev. Geol. Amér. Central, 44, 119-130 (2011).

5. B. Das. Fundamentos de Ingeniería Geotécnica. (Thomson Learning, México, 2015).

6. G. Schosinsky, and M. Losilla, M., Rev. Geol. Amér. Central, 23, 43-55 (2000).

7. M. Pineda, Análisis de flujo en dos dimensiones de la ladera noroeste del Monumento Arqueológico Nacional Guayabo, (Trabajo final de graduación, Universidad de Costa Rica, 2015).

8. Van Genuchten, M., Leij, F., Yates, S., The RETC Code for quantifying the hydraulic functions of unsaturated soils (EPA, USA, 1991) 